\title{
The effect of zinc contamination from electricity pylons. Genetic constraints on selection for zinc tolerance
}

\author{
S. A. K. AL-HIYALY, T. McNEILLY,* A. D. BRADSHAW AND A. M. MORTIMER \\ Department of Environmental and Evolutionary Biology, University of Liverpool, PO Box 147, Liverpool L69 $3 B X, U K$
}

\begin{abstract}
Zinc tolerance, based on root growth in zinc-containing solutions, was examined in samples of 30 Agrostis capillaris L. individuals collected from populations beneath five electricity pylons in North Wales. The populations were found to vary in zinc tolerance. Three of them contained individuals whose tolerance ranged from low to high, one population consisted of individuals with low to moderate tolerance, whilst the fifth population $(\mathrm{ZK}-180)$ contained no tolerant individuals. Differences in zinc tolerance were also found between seedlings raised from five seed populations collected from plants growing in the uncontaminated pasture areas adjacent to four of those pylons, and one further pylon in the same area. The population adjacent to pylon ZK-180 consistently showed little sign of tolerant individuals. Samples of seeds collected from the populations in the uncontaminated areas surrounding each pylon, and likely to have been the origin of the pylon populations were grown at a concentration of $15 \mu \mathrm{g} \mathrm{Zn} \mathrm{cm}^{-3}$, and root lengths of 105 randomly chosen seedlings from each were measured. The means and variance of tolerances of four of the five did not differ, but all were significantly higher than that adjacent to pylon ZK-180. Two cycles of selection and breeding for increased zinc tolerance were carried out using seed samples collected from four of the five populations of adults collected beneath pylons examined previously, and including population ZK-180. Marked increases in tolerance were effected in three of the four populations; no corresponding increase in tolerance was achieved for population ZK-180. It is concluded from these findings that the lack of zinc tolerance beneath pylon ZK-180 is due to the absence of appropriate variation in zinc tolerance within that population, and in potential colonizing material adjacent to it, a situation which contrasts with that for the other three pylons.
\end{abstract}

Keywords: Agrostis capillaris, breeding constraints, selection, zinc tolerance.

\section{Introduction}

A shift in the genetic structure of populations of organisms in the wild is generally considered as the normal response to environmental change, provided that the change is (i) sufficient to impose selection powerful enough to cause such a shift, and (ii) greater than can be accommodated by plastic reponses in the phenotype However, it is well known amongst plant breeders that there are limits to what may be achieved by artificial selection because of a lack of appropriate genetic variation (Bradshaw 1984a). To what extent is evolution in the wild constrained by this same phenomenon?

Metal-contaminated sites are extreme environments

*Correspondence: T. McNeilly. for seed germination (Thompson, 1987), plant establishment, (Farrow, 1983; Thompson, 1987), and growth. For such sites to be colonized, the propagules of a particular species have to migrate onto such sites, and also have the appropriate genetic variability which allows them to overcome severe environmental factors, both physical and chemical, before thay can become established. These constraints, both genetic and ecological, are clearly overcome in the case of a number of grass and herb species which are regularly found colonizing metal-contaminated sites. The populations of these species on such sites can be shown to have evolved metal-tolerant races (Antonovics et al., 1971; Bradshaw, 1975; Ernst, 1976; McNeilly, 1987). The potential for this evolution has been shown by experimental screening of large numbers of seedlings of normal populations either on ameliorated metal-con- 
taminated wastes (Antonovics, 1966; Khan, 1969; Karataglis, 1980), or using solution media containing metals at appropriate toxic concentrations (Symeonidis et al., 1985; Ingram, 1987; Al-Hiyaly, 1989). A low frequency of tolerant individuals, only two or three individuals per thousand, can be found. These provide the starting point for the evolution of fully tolerant populations (Walley et al., 1974; Gartside \& McNeilly, 1974; Wu et al., 1975).

The number of species which have been found colonizing heavy metal contaminated sites originating from past mining or smelting activity is limited, despite the occurrence of many other species in the surrounding vegetation. In the case of copper and zinc tolerance it has been shown that these colonists are only those species which possess the necessary variability to be able to evolve copper tolerance, although the differences between the species composition of mine and normal sites may also reflect differences in tolerance to more normal ecological factors, such as the occurrence of drought or low nutrient levels.

It is noticeable, however, that apparently similar sites differ in the species that colonize them. This could be due to undetected ecological differences between these sites or perhaps stochastic differences in the availability of the relevant species in the neighbourhood. But it could also be due to variation in the ability to evolve metal tolerance, analogous to the situation in crop plants, where the same variation is certainly not found in all populations (e.g. Qualset, 1975). Any assessment of such a possibility, that colonization and hence the differences in species composition between sites is prevented by the lack of appropriate genetic variance for metal tolerance, cannot be undertaken if the sites being compared differ markedly in origin and general ecology. It might be possible, however, in a series of contaminated sites which have similar origins and are effectively replicated in space but not in time. This apparently improbable situation does in fact occur under electricity transmission lines.

The occurrence of zinc contamination of soils beneath individual electricity pylons sufficient to cause the evolution of zinc-tolerant populations of a number of grass species has recently been reported (Al-Hiyaly et al., 1988, 1990). The separate pylons provide a unique series of replicated situations in space, since the dates of erection of pylons within a single line are virtually the same. A. capillaris is found to be the main colonizer of the toxic areas beneath almost all pylons that have been examined on acid upland soils in Wales and N.W. England (Al-Hiyaly, 1989). Nevertheless, even within the limits of the small samples collected, zinc-tolerant plants were not found beneath every pylon (Al-Hiyaly et al., 1988). It was suggested that this was due to the lack of tolerant individuals in the original populations growing beneath, and in the immediate vicinity of, those pylons when they were erected. In the light of the findings of Symeonidis et al., (1985) of the stochastic occurrence of metal tolerance in normal populations of $A$. capillaris, this is not impossible.

There are bare areas beneath a significant number of pylons. These are particularly where tolerant populations are not found (Al-Hiyaly, 1989). Colonization of these areas could be determined by factors other than zinc toxicity, since seeds from neighbouring populations must reach such areas, germinate, and overcome extreme soil factors unrelated to zinc before they can establish. All these processes are subject to various degrees of perturbation through erosion by surface runoff of rainwater, impact of treading and grazing by herbivores, and frost heaving. Nevertheless lack of colonization could be due to lack of tolerance.

The genetic constraints on the evolution of zinc tolerance beneath pylons have therefore been investigated. First, the pattern of zinc tolerance in samples of 30 individuals of $A$. capillaris from beneath five pylons have been examined, and related to the occurrence of genes for tolerance in the populations growing on uncontaminated soil surrounding the pylons. Secondly, the impact of two cycles of artificial selection for improved zinc tolerance has been examined in four populations, two of which were included in the first part of the work, to test directly whether genes for enhanced zinc tolerance were indeed present in these sub-pylon populations.

\section{Materials and methods}

\section{Experiment 1. Zinc tolerance in the populations beneath five pylons}

Thirty individuals of $A$. capillaris were randomly sampled from each of the five populations occurring beneath five pylons in autumn 1987. Three of the pylons were from one pylon line erected in 1956, ZK51, ZK-52, ZK-180, and two from others, ZKA-12 erected in 1967, and 4ZB-76 erected in 1966. All the pylons were on similar acid upland grassland in North Wales within $60 \mathrm{~km}$ of each other. Unfortunately because of variations in management, topography, and drainage characteristics of the soils beneath successive pylons within a single line, it was impossible to sample A. capillaris from five adjacent pylons.

At least two connected tillers from each plant were transplanted into standard potting soil and grown in an unheated and unlit glasshouse for a minimum of 3 months before testing for zinc tolerance. Tolerance to 
zinc was assessed at $7.5 \mu \mathrm{g} \mathrm{Zn} \mathrm{cm}^{-3}$ following the standard parallel root growth testing method (Bradshaw \& McNeilly, 1981) in a randomized block design with three replicates.

\section{Experiment 2. Zinc tolerance in the populations adjacent to five pylons}

Seed of five $A$. capillaris populations from the pastures on uncontaminated soil surrounding five pylons, likely to have been the origin of the pylon populations, were collected in late summer 1988. Four of these were the same as in Experiment 1, ZK-52, ZK-180, ZK-A12, and $4 \mathrm{ZB}-76$, and one other, 4ZB-39. Seed was taken from a zone outside each pylon not less than $30 \mathrm{~m}$ but not more than $50 \mathrm{~m}$ from each. The choice of these pylons was determined first by the availability of seed, and secondly, and most importantly, so as to include pylons which, from the results of Experiment 1, had been shown to support predominantly either tolerant or non-tolerant populations.

(i) General response to zinc. This experiment was conducted to assess the response of populations to increasing zinc concentration in solution culture, and to determine the minimum concentration at which maximum root inhibition would occur. Fifteen to 20 seeds of each population were sown on the surface of rafts of black alkathene beads three layers deep, floated on the surface of dilute nutrient solution without phosphate (Rorison in Hewitt, 1966) containing 0, 2.5, 5.0, 7.5, 12.5 and $15.0 \mu \mathrm{g} \mathrm{Zn} \mathrm{cm}^{-3}$ in a randomized block design with three replicates, in a growth room at $22^{\circ} \mathrm{C}$. Seedlings were grown in perspex chambers to maintain high humidity and minimize evaporation of the culture solutions. After 14 days, 10 seedlings per beaker were randomly chosen and the length of their longest root measured.

(ii) Screening test. A zinc concentration of $15 \mu \mathrm{g} \mathrm{Zn}$ $\mathrm{cm}^{-3}$ was used, determined from Experiment 2(i) as the minimum concentration required to produce maximum inhibition of root growth. Fifteen thousand seeds per population, estimated by weight, were sown on black alkathene beads floated on dilute nutrient solution as in Experiment 2(i) but containing $15.0 \mu \mathrm{g} \mathrm{Zn}$ $\mathrm{cm}^{-3}$ in $23 \times 23 \times 10 \mathrm{~cm}$ clear plastic containers, each having approximately 5000 seeds, in a randomized block design with three replicates, under the same growing conditions as Experiment 2(i) above. After 4 weeks, 105 seedlings per population ( 35 per replicate) were randomly chosen and their longest root lengths measured.

\section{Experiment 3. The effects of two cycles of selection and breeding for zinc tolerance on four populations}

To assess how far there were real genetic constraints on the evolution of zinc tolerance, the occurrence or not of zinc-tolerant adult populations beneath particular pylons (Experiment 1), was parallelled by artificial selection for zinc tolerance in seed samples of different pylon populations.

(i) Screening. Samples of $A$. capillaris seed from the populations actually growing beneath pylons $\mathrm{ZK}-50$, ZK-51, ZK-52, and ZK-180, were collected in summer 1987. The choice was governed, as in Experiment 2 (i) by seed availability, and adult population tolerance. These seed populations were first examined for their general response to increasing zinc as in Experiment 2(i) using six zinc concentrations.

From this, a zinc concentration of $12.5 \mu \mathrm{g} \mathrm{Zn} \mathrm{cm}^{-3}$, just lower than that which caused seedling root growth inhibition, was used to select as many as possible of the best rooted seedlings of these populations for polycrossing and a subsequent further cycle of selection. Depending upon the number of seeds available, 7000 to 10,000 seeds per population were screened following the methods and conditions described for Experiment 2(ii). After 4 weeks' growth, the 30 best rooted seedlings $\left(\mathbf{S P}_{0}\right)$ were selected from each population and their root lengths measured. The seedlings were planted individually into standard potting soil in plastic pots. A further sample of 70 seedlings per population $\left(\mathbf{S}_{0}\right)$ was chosen at random, and their longest root lengths measured. The transplanted $\mathbf{S P}_{0}$ seedlings were placed in an unheated and unlit polythene tunnel house until April 1988. The plants were then taken into a glasshouse at $20^{\circ} \mathrm{C}$ and with natural daylength supplmented with a $16 \mathrm{~h}$ photoperiod supplied by mercury vapour lamps. Under these conditions, flowering began in mid-May, and the plants from each sub-pylon population allowed to polycross naturally, each population being isolated in a separate glasshouse. In late July, seed, hereafter referred to as $\mathbf{S}_{1}$, was collected from the plants of each population.

In August, a second selection was made by screening 15,000 seeds of each $\mathbf{S}_{1}$ population, this time at $15 \mu \mathrm{g}$ $\mathrm{Zn} \mathrm{cm}^{-3}$, using the procedure outlined above. The longest root lengths of the 30 best rooted seedlings $\left(\mathbf{S P}_{1}\right)$ from each of the populations were measured, and the seedlings were then planted individually in pots of standard potting soil. A sample of 70 seedlings per population was then taken at random and their root lengths measured to provide data for the base unselected population $\left(\mathbf{S}_{1}\right)$. The 30 transplanted seedlings were again transferred to and overwintered in an 
unheated and unlit polythene tunnel house. In late March 1989 induction of flowering was begun for these $\mathbf{S P}_{1}$ plants by placing them in the same conditions as previously used for generation $\mathbf{S P}_{0}$ plants. In late May flowering began and the plants of each population were separated in individual glasshouses and allowed to polycross naturally. Seed, denoted $\mathbf{S}_{2}$, was harvested from the plants in mid-June and dried at room temperature.

The realised heritabilities of both $\mathbf{S}_{1}$ and $\mathbf{S}_{2}$ generations were determined for each pylon population at 12.5 and $15.0 \mu \mathrm{g} \mathrm{Zn} \mathrm{cm}{ }^{-3}$, respectively, following Falconer (1983), in which realized heritability

$$
h_{n}^{2}=\frac{\text { Response }(R)}{\text { Selection differential }(S)}
$$

where $R=$ (Selected progeny mean - unselected parental mean) and $S=$ (Selected parental mean - unselected patental mean).
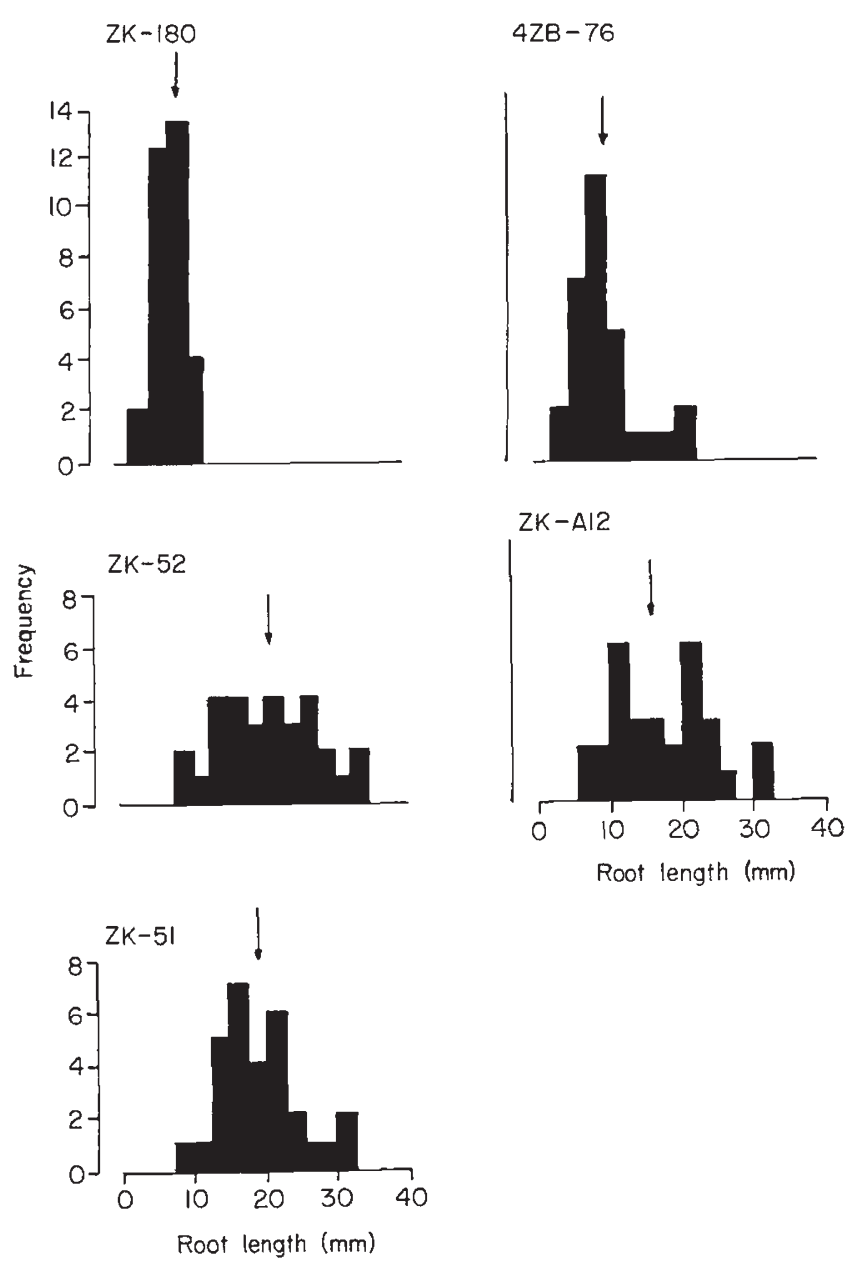

Fig. 1 Experiment 1. Mean root lengths of 30 plants of Agrostis capillaris from beneath five different pylons tested at $7.5 \mu \mathrm{g} \mathrm{Zn} \mathrm{cm}^{-3}$ (means indicated by arrows). (ii) General response. Seed samples of $\mathbf{S}_{0}, \mathbf{S}_{1}$, and $\mathbf{S}_{2}$ generations of all populations were tested with two control samples, one from a mine and one from an uncontaminated site, in six zinc concentrations following the method used in Experiment 2(i). After 2 weeks' growth the longest root lengths of 10 randomly chosen seedlings were measured.

(iii) Final assessment. Finally, samples of both $\mathbf{S}_{1}$ and $\mathbf{S}_{2}$ generations of each population were screened at 20 $\mu \mathrm{g} \mathrm{Zn} \mathrm{cm}{ }^{-3}$ for 3 weeks and measurements of longest root lengths of 100 randomly chosen seedlings per generation per population taken as in Experiment 2(i).

\section{Results}

Since previous work (Gartside, 1973; Walley et al., 1974; Wu et al., 1975; Symeonidis et al., 1985) has already shown that artificially selected seedlings show enhanced metal tolerance as adults, and Ingram (1987) found a very high correlation between the copper tolerance of seedlings and those same seedlings when adults, no tolerance test for the selected individuals as adults was carried out. The data will be considered in terms of the variation in response to zinc between populations, and between individuals within populations, which reflect the potential for zinc tolerance to evolve from those populations under the appropriate selection pressure.

\section{Experiment 1. Zinc tolerance in the populations beneath five pylons}

Root lengths and tolerance indices of the 30 plants from each population are presented in Figs 1 and 2, respectively.

The plants from beneath pylons $\mathrm{ZK}-51, \mathrm{ZK}-52$, and $\mathrm{ZK}-\mathrm{A} 12$ had the longest roots at $7.5 \mu \mathrm{g} \mathrm{Zn} \mathrm{cm}{ }^{-3}$, ranging from 18 to $75 \mathrm{~mm}$. These gave tolerance indices ranging from 15.9 to $74.6 \%$. The plants from $4 \mathrm{ZB}-76$ had root lengths at $7.5 \mu \mathrm{g} \mathrm{Zn} \mathrm{cm}^{-3}$ varying from 13 to $45 \mathrm{~mm}$, and tolerance indices ranging from 9.1 to $46.5 \%$, although all but four individuals had tolerance indices less than $30 \%$. All the plants from $\mathrm{ZK}-180$ had root lengths ranging from 9 to $21 \mathrm{~mm}$, and corresponding tolerance indices less than $20 \%$.

Analyses of variance of root lengths and tolerance indices revealed significant differences between populations sampled from the five pylons $(P<0.001)$ and between individuals within these populations, $(P<0.001)$. The differences in mean root lengths and tolerance indices between ZK-52 and ZK-A12 plants were not significant (Tukey; multiple range test), but both populations had significantly greater root lengths 

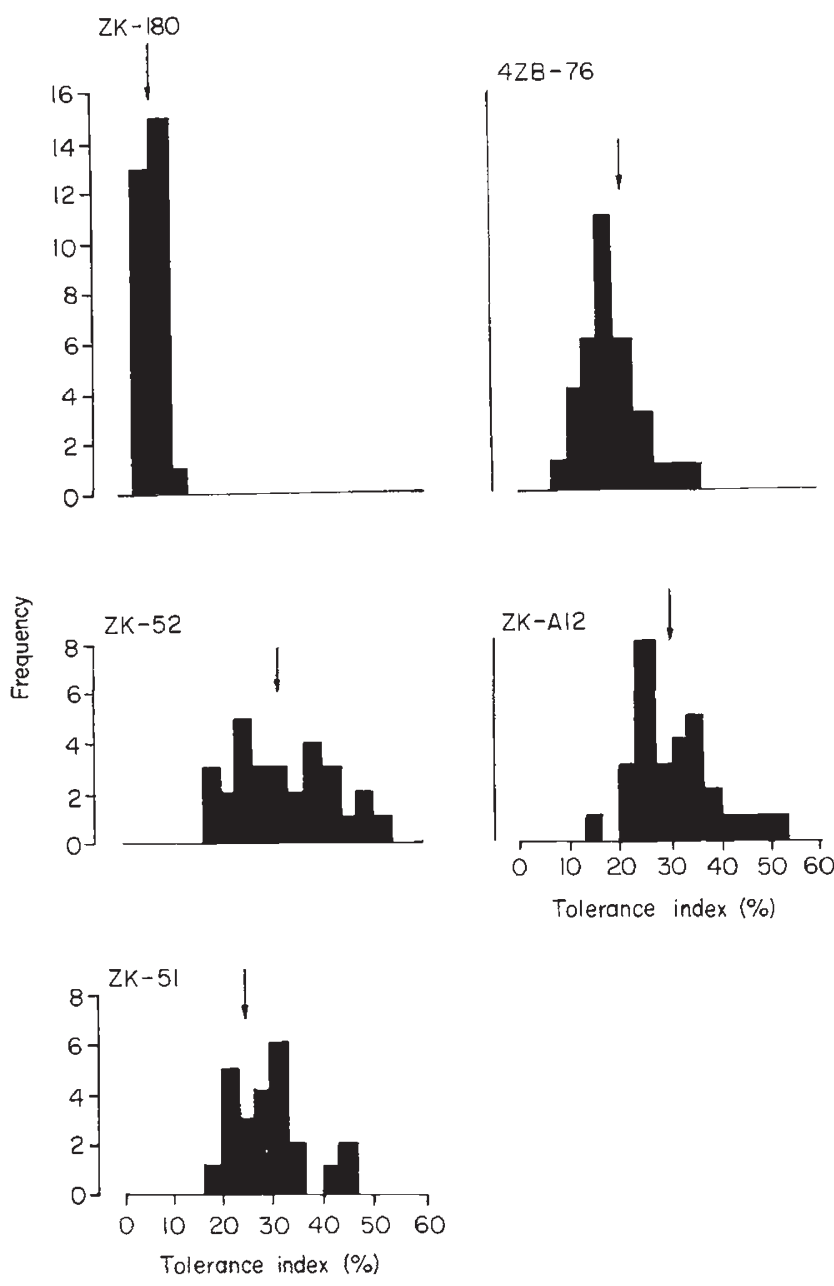

Fig. 2 Experiment 1. Mean tolerance indices of 30 plants of Agrostis capillaris from beneath five different pylons (means indicated by arrows).

and tolerance indices $(P<0.05)$ than plants from $\mathrm{ZK}$ $51, \mathrm{ZK}-180$, and $4 \mathrm{ZB}-76$. The differences between the latter three populations were significant for both measures of tolerance at $P<0.05$.

\section{Experiment 2. Zinc tolerance in adjacent seed populations}

(i) General response to zinc. There were significant differences $(P<0.01)$ between populations and different zinc concentrations $(P<0.001)$ in seedling root growth (Fig. 3). The populations had significantly different responses to increasing zinc (interaction $\mathrm{P} \times \mathrm{C}$ significant at $P<0.001)$. At all zinc concentrations other than the control solution without zinc, the population from pylon ZK-180 consistently had the shortest roots. However this does not show the detailed pattern of the variability. From the results of this experiment, a

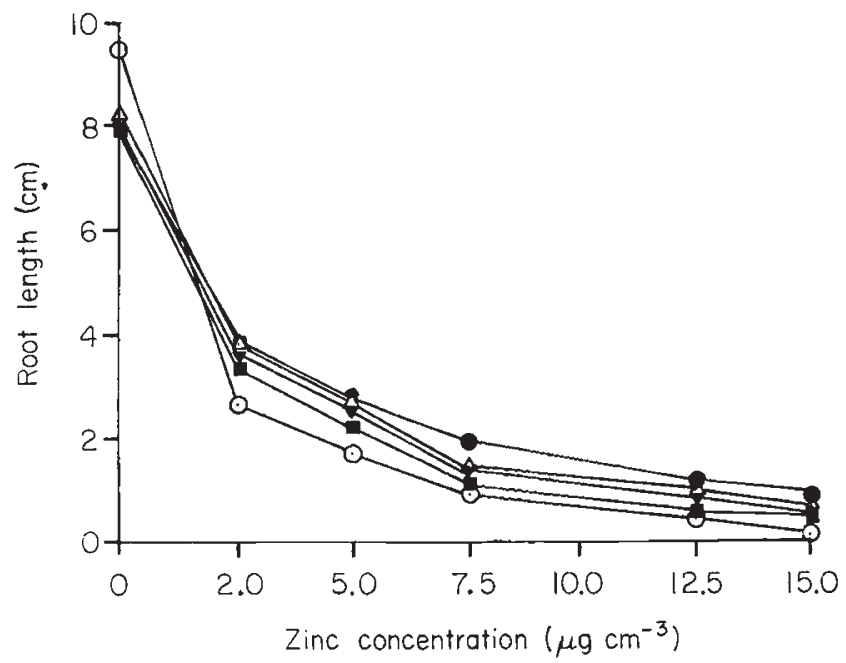

Fig. 3 Experiment 2(i). Mean root lengths of seedlings of Agrostis capillaris populations adjacent to five pylons, grown at six zinc concentrations. $\bullet=\mathrm{ZK}-52, \mathrm{O}=\mathrm{ZK}-180, \Delta=\mathrm{ZK}-$ $\mathrm{A} 12, \boldsymbol{\nabla}=4 \mathrm{ZB}-76, \boldsymbol{\Delta}=4 \mathrm{ZB}-39$.

concentration of $15.0 \mu \mathrm{g} \mathrm{Zn} \mathrm{cm}$ cm $^{-3}$ was therefore chosen for detailed analysis of the populations.

(ii) Variability in root growth at $15.0 \mu \mathrm{g} \mathrm{cm}^{-3}$ (Fig. 4). There were significant differences $(P<0.001)$ between the mean root lengths of the selected seedlings from the five populations. The means for populations $\mathrm{ZK}-52$ and ZK-A12, and 4ZB-39 and 4ZB-76 did not differ significantly from each other, but the mean of population ZK-180 was significantly less than these four populations ( $t$-test comparison). Population $\mathrm{ZK}-180$ was also significantly less variable than the other four populations $(P<0.001)$, and $4 \mathrm{ZB}-76$ was less variable than populations $4 \mathrm{ZB}-39(P<0.01)$, and ZK-A12 and ZK-52 $(P<0.001 ; F$-test $)$. Population ZB-180 was quite distinct in lacking any seedlings with root lengths of more than $20 \mathrm{~mm}$. This is similar to the performance shown by the adult plants collected from the same pylon in Experiment 1.

\section{Experiment 3. Two cycles of selection and breeding}

(i) Screening. The mean root lengths in $12.5 \mu \mathrm{g} \mathrm{Zn} \mathrm{cm}^{-3}$ of samples from the original populations $\left(\mathbf{S}_{0}\right)$, for the 30 seedlings having the longest roots from each of the populations, $\mathbf{S P}_{0}$, and the polycross progeny of the $\mathbf{S P}_{0}$ generation, $\mathbf{S}_{1}$, are given in Table 1 . Comparable data for $\mathbf{S}_{1}, \mathbf{S} \mathbf{P}_{1}$, and $\mathbf{S} \mathbf{P}_{1}$ generation polycross progeny, $\mathbf{S}_{2}$, grown in $15.0 \mu \mathrm{g} \mathrm{Zn} \mathrm{cm}^{-3}$ are also given in Table 1 .

At $15.0 \mu \mathrm{g} \mathrm{Zn} \mathrm{cm}^{-3}$ the $\mathbf{S}_{1}$ generations were significantly greater $(P<0.05)$, by approximately $1.5,2.5$ and 

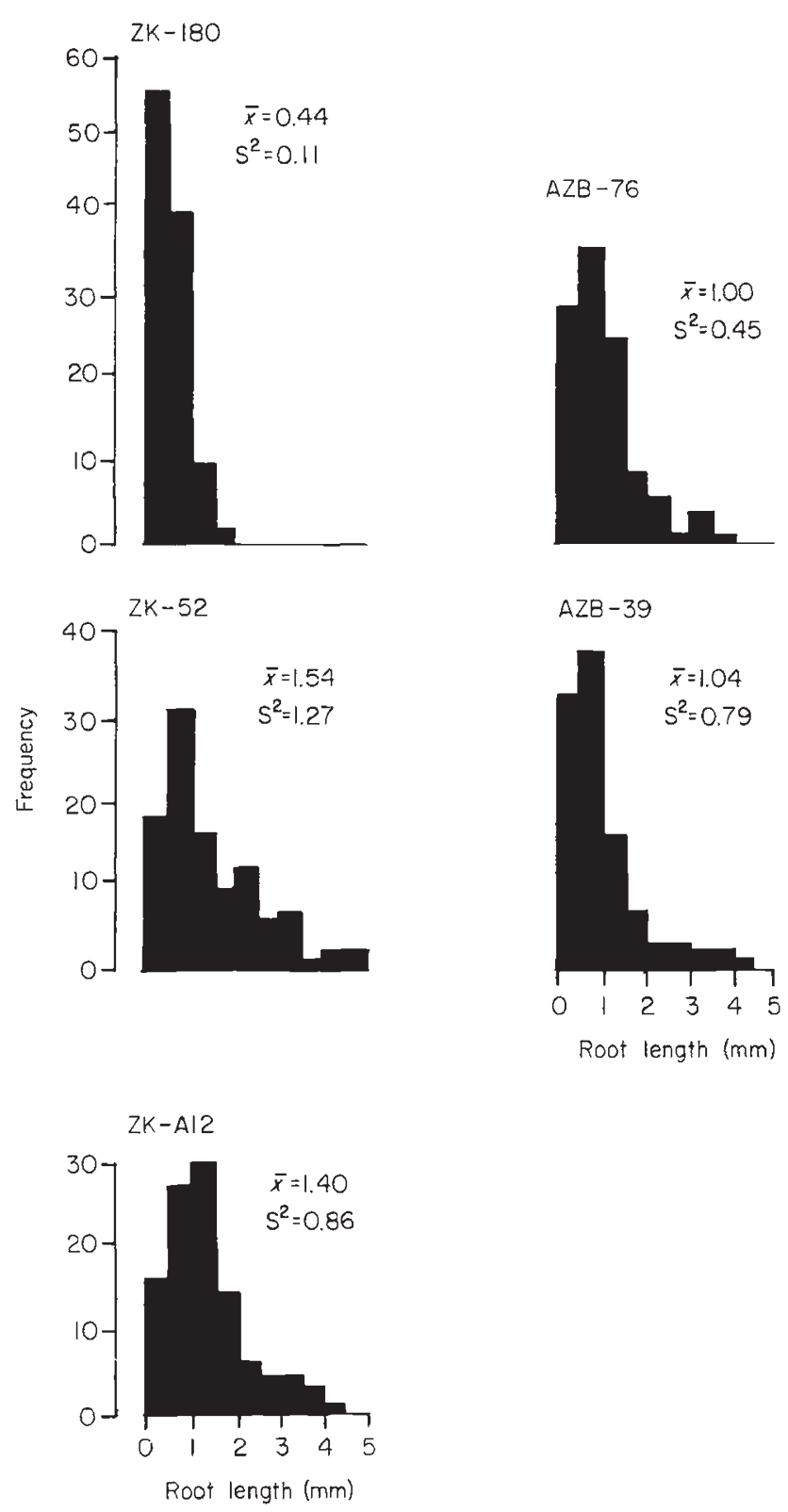

Fig. 4 Experiment 2(ii). Root lengths of 105 randomly chosen seedlings of each of five Agrostis capillaris populations adjacent to different pylons, grown at $15 \mu \mathrm{g} \mathrm{Zn} \mathrm{cm}{ }^{-3}$ $\left(S^{2}=\right.$ within population variance; $\bar{x}=$ means $)$.

3.5 times, than their $\mathbf{S}_{0}$ generations for $\mathrm{ZK}-50, \mathrm{ZK}-51$, and ZK-52, respectively. However there was almost no change for population $\mathrm{ZK}-180$. The $\mathbf{S}_{2}$ generations were again significantly greater $(P<0.05)$ by almost two times (ZK-50), one and a half times (ZK-51), and two times $(\mathrm{ZK}-52)$ than those of the $\mathbf{S}_{1}$ generations. The data for ZK-180 showed small but nonsignificant changes in root lengths from $S_{1}$ to $S_{2}$.

At the completion of two cycles of selection and breeding, the general response of $\mathbf{S}_{0}, \mathbf{S}_{1}$, and $\mathbf{S}_{2}$ genera-
Table 1 Experiment 3(i). Screening. Mean seedling longest root lengths in two zinc concentrations for unselected $\left(\mathbf{S}_{0}\right)$ samples from four Agrostis capillaris pylon populations, and for generations resulting from two cycles of selection within them for increased zinc tolerance

\begin{tabular}{|c|c|c|c|c|c|c|}
\hline \multirow[b]{2}{*}{ Pylon population } & \multicolumn{3}{|c|}{$12.5 \mu \mathrm{g} \mathrm{Zn} \mathrm{cm}^{-3}$} & \multicolumn{3}{|c|}{$15.0 \mu \mathrm{g} \mathrm{Zn} \mathrm{cm}^{-3}$} \\
\hline & $\mathrm{S}_{0}$ & $\mathrm{SP}_{0}$ & $\mathrm{~S}_{1}$ & $S_{1}$ & $\mathrm{SP}_{1}$ & $\mathrm{~S}_{2}$ \\
\hline ZK-50 & 0.95 & 2.57 & 1.67 & 1.50 & 4.42 & 2.57 \\
\hline ZK-51 & 0.91 & 2.79 & 1.64 & 1.45 & 4.81 & 2.53 \\
\hline ZK-52 & 1.15 & 3.07 & 1.91 & 1.68 & 4.77 & 2.85 \\
\hline Zk-180 & 0.48 & 1.34 & 0.57 & 0.36 & 1.31 & 0.52 \\
\hline
\end{tabular}

tions of the four seed populations, as well as seed from control mine and non-mine plants, were assessed at six zinc concentrations (Fig. 5).

Realized heritability values of the populations $\mathrm{ZK}$ 50, ZK-51, and ZK-52 were $0.44,0.39,0.40$, and 0.37 . $0.32,0.38$ for $\mathbf{S}_{1}$ and $\mathbf{S}_{2}$ generations, respectively, whilst for population $\mathrm{ZK}-180$ the corresponding values were 0.10 and 0.17 .

(ii) General response. Analyses of variance of the data for the response of the $\mathbf{S}_{1}, \mathbf{S}_{2}$, and $\mathbf{S}_{3}$ generations of these populations to increasing zinc are shown in Table 2. The analysis assumes a mixed model analysis of variance, with blocks, concentrations (of zinc), and populations (pylons), as fixed effects, and generations as a random effect nested under populations. Although some degree of heterogeneity of error variance is evident in the raw data, and this is improved by square root transformation, the patterns of significance amongst items is unaltered. Table 2 therefore presents data derived from analysis of the raw data. There were highly significant differences between the populations in their responses to selection. Whilst there were significant differences due to selection between generations for populations ZK-50, ZK-51, and ZK-52, there was no response to selection at any concentration in $\mathrm{ZK}$ 180. Responses of the four populations to selection differ across the zinc concentrations used for testing, (Generations within $(\mathrm{P} \times \mathrm{C})$ significant for all four populations: Fig. 5.). This reflects the relatively modest response shown when the material is tested at low zinc concentrations, in contrast to the greater responses shown at intermediate and higher zinc concentrations (Fig. 5).

(iii) Final assessment. It is clear from the histograms for the individual populations (Fig. 6) that the difference in response between the populations was due to the 

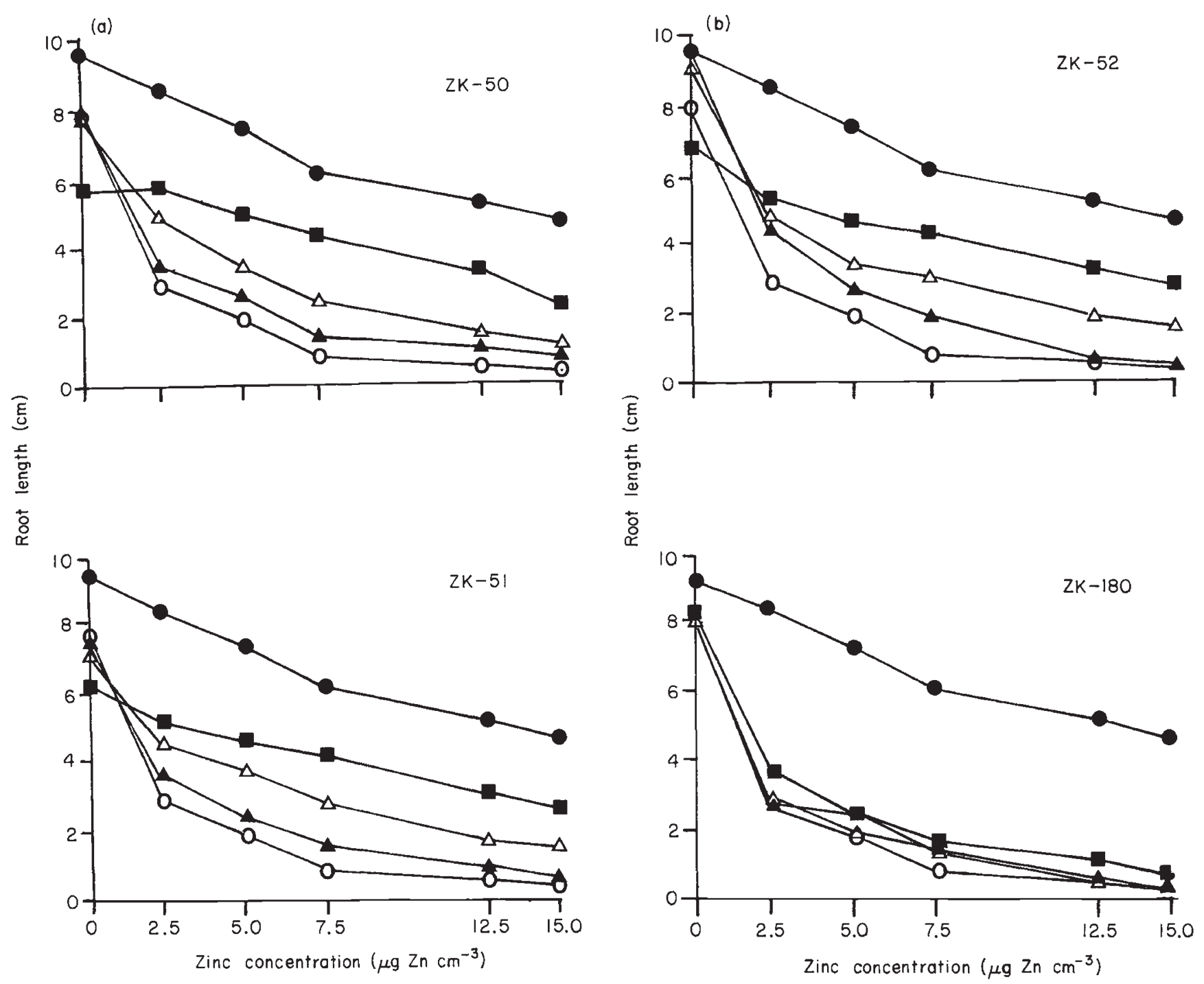

Fig. 5 Experiment 3(ii). Mean root lengths of $\mathbf{S}_{0}, \mathbf{S}_{1}$ and $\mathbf{S}_{2}$ generations of Agrostis capillaris populations from beneath four pylons, with two controls of tolerant zinc mine and non-tolerant seedlings at six zinc concentrations. $\bullet=$ Mine, $\mathrm{O}=$ control, $\Delta=\mathbf{S}_{0}, \mathbf{A}=\mathbf{S}_{1}, \boldsymbol{\bullet}=\mathbf{S}_{2}$.

marked increase in the number of seedlings with root lengths greater than $30 \mathrm{~mm}$ in the $\mathbf{S}_{2}$ generation of the populations from beneath pylons ZK-50, ZK-51, and ZK-52, but not in that from pylon ZK-180. Mean root lengths of the $\mathbf{S}_{1}$ and $\mathbf{S}_{2}$ selected generations derived from the ZK-180 population were by contrast, almost indentical to the $\mathbf{S}_{0}$ generation, and in all three generations, $93-97 \%$ of seedlings had root lengths of less than $20 \mathrm{~mm}$, the remaining $3-5 \%$ measuring less than $30 \mathrm{~mm}$.

\section{Discussion}

These populations of Agrostis capillaris growing beneath electricity pylons are in the early stages of a new evolutionary pathway. Nevertheless it is clear from these experiments that the populations can show enhanced zinc tolerance distinctly greater than that shown by normal populations, but usually less than that shown by plants in populations growing on abandoned $\mathrm{Zn} / \mathrm{Pb}$ mine sites. However, tolerant individuals are not found beneath every pylon, and equally, not all the individuals beneath a single pylon are of equivalent tolerance. The tolerances of the populations from pylons ZK-51, ZK-52, and ZKA-12 were markedly greater than for those for $\mathrm{ZK}-180$ and $4 \mathrm{ZB}-76$, as were their variances. ZK-180 had a significantly lower variance than the other four populations, and $4 \mathrm{ZB}-76$ was significantly less variable than populations $\mathrm{ZK}-51$ and $\mathrm{ZK}-52$. This was undoubtedly due to the absence 
Table 2 Experiment 3(ii). General response to zinc. Analysis of variance for mean root lengths of $\mathbf{S}_{0}, \mathbf{S}_{1}$ and $\mathbf{S}_{2}$ generations of A. capillaris populations grown in six zinc concentrations

\begin{tabular}{lccc}
\hline Source & d.f. & Mean square & $F$-value $\dagger$ \\
\hline Blocks & 2 & 0.06 & $0.49^{\text {ns }}$ \\
Populations $(\mathrm{P})$ & 3 & 14.50 & $1.90^{\text {ns }}$ \\
Concentrations $(\mathrm{C})$ & 5 & 202.85 & $101.82^{* * *}$ \\
Generations within populations & 8 & 7.63 & $3.82^{* *}$ \\
$\quad$ Gens within P1 & 2 & 11.08 & $5.56^{* *}$ \\
Gens within P2 & 2 & 11.13 & $5.58^{* *}$ \\
Gens within P3 & 2 & 7.62 & $3.82^{*}$ \\
Gens within P4 & 2 & 0.68 & $0.34^{\text {ns }}$ \\
Interaction (P×C) & 15 & 2.65 & $1.32^{\text {ns }}$ \\
Generations within (P×C) & 40 & 1.99 & $16.01^{* * *}$ \\
Gens within P1 $\times$ C & 10 & 2.85 & $22.89^{* * *}$ \\
Gens within P2 $\times$ C & 10 & 1.34 & $10.81^{* * *}$ \\
Gens within P3 $\times$ C & 10 & 3.51 & $28.26^{* * *}$ \\
Gens within P4 $\times$ C & 10 & 0.26 & $2.11^{*}$ \\
Error & 142 & 0.12 & \\
Total & 215 & & \\
\hline
\end{tabular}

†ns, $P>0.05 ;{ }^{*} P \leqslant 0.05 ;{ }^{* *} P \leqslant 0.01 ;{ }^{* * *} P \leqslant 0.001$.

of tolerant individuals beneath $\mathrm{ZK}-180$, and the predominance of non-tolerant individuals beneath $4 \mathrm{ZB}-$ 76.

Similar differences in tolerances between populations have been reported for $A$. capillaris populations from other zinc-contaminated sites (Karataglis, 1980), and it was suggested that this was due to the selection pressure for tolerance on some of these sites being too low to promote the evolution of a uniformly high level of tolerance. In the different pylon sites examined here, however, the selection pressures operating due to zinc must have been very similar; soil $\mathrm{pH}$, organic matter content, and nutrient status were also similar. Thus differences in selection pressures are unlikely to be responsible for the differences in zinc tolerance at different pylons. An alternative explanation is that it is the absence of genes for zinc tolerance from some of these populations which prevents the evolution of zinctolerant populations beneath those pylons. The preliminary screening suggested that this might be likely at pylon ZK-180. At 4ZB-76 the few individuals only of low tolerance might be because the population was of recent origin since the pylon was more recent. With time the frequency of tolerant individuals might increase, through transgressive segregants from the intercrossing of established moderately tolerant individuals.

The absence of individuals having high tolerance equivalent to that of mine plants can be explained in a similar way. Because of the polygenic basis of tolerance (Gartside \& McNeilly, 1974; Al-Hiyaly, 1989), the presence or not in the parental populations of each of the favoured genes required for high tolerance will be subject to the same chance factors as the genes for the initial evolution of tolerance.

The results from Experiment 2, where the root growth in reponse to increasing concentrations of zinc was examined in the seed of populations growing on normal soils adjacent to four of the pylons sampled in Experiment 1, confirm the conclusion that absence of tolerant plants beneath pylons is due to that lack of tolerant genes in the surrounding potentially parental populations. In particular, no tolerant individuals were found either beneath pylon ZK-180 or in the surrounding population. This is in marked contrast to the other three populations, all of which showed pronounced variation in root growth in solutions containing $15 \mu \mathrm{g} \mathrm{Zn} \mathrm{cm} \mathrm{cm}^{-3}$. Such populations have the necessary genetic variation to allow the evolution of zinc tolerance.

A direct test of the conclusions reached from the first two experiments is provided by the results from the experiment involving two cycles of selection and breeding using seed material taken from under the pylons. It is clear from these that three of the populations examined have significant amounts of additive genetic variation for zinc tolerance within them, so that selection readily increases zinc tolerance. This is particularly clear from the remarkable increase in the number of long rooted individuals (Fig. 6) when the $\mathbf{S}_{2}$ generations of these three populations was screened at $20 \mu \mathrm{g} \mathrm{Zn} \mathrm{cm}^{-3}$. It is also evident from the data for realized (narrow sense) heritability estimates of 0.39 to 0.44 for the $\mathbf{S}_{1}$ generations, and 0.32 to 0.38 for the $\mathbf{S}_{2}$ 
$S_{1}$ Generation
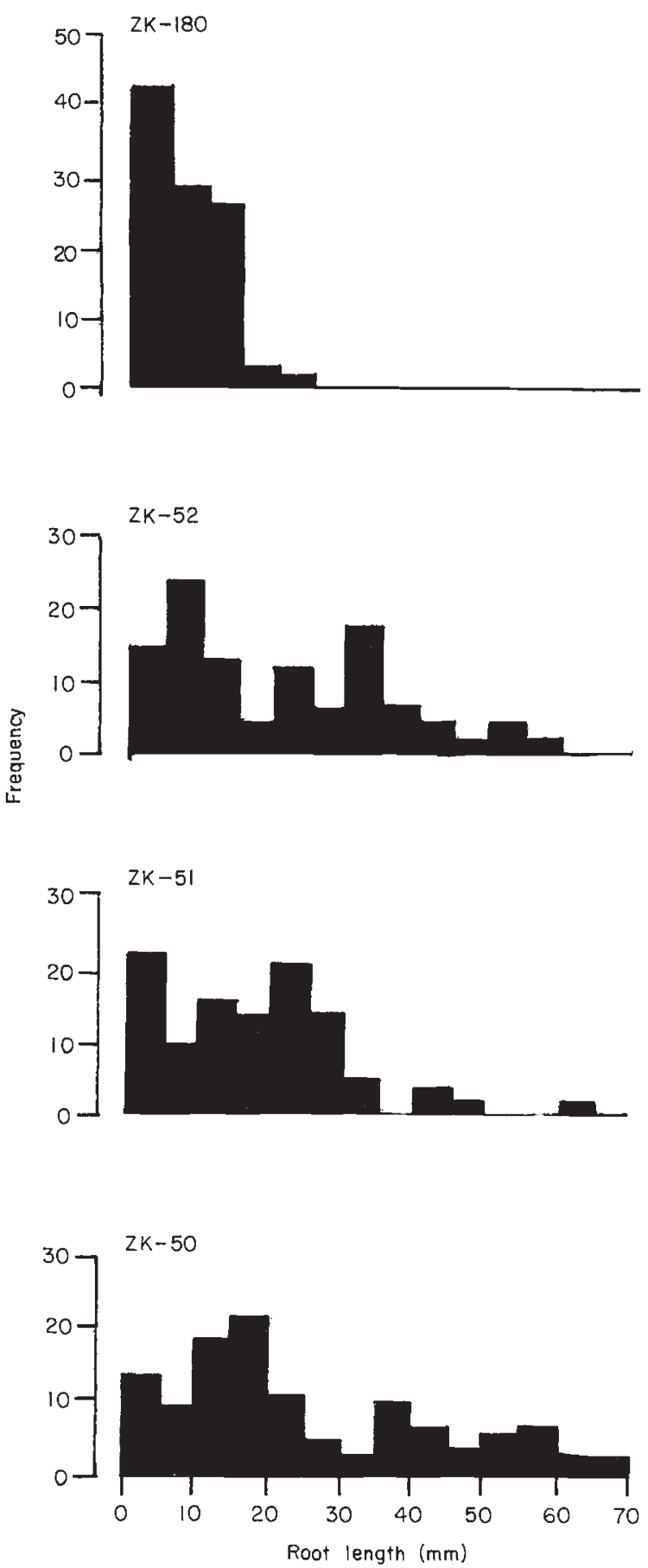

$S_{2}$ Generation
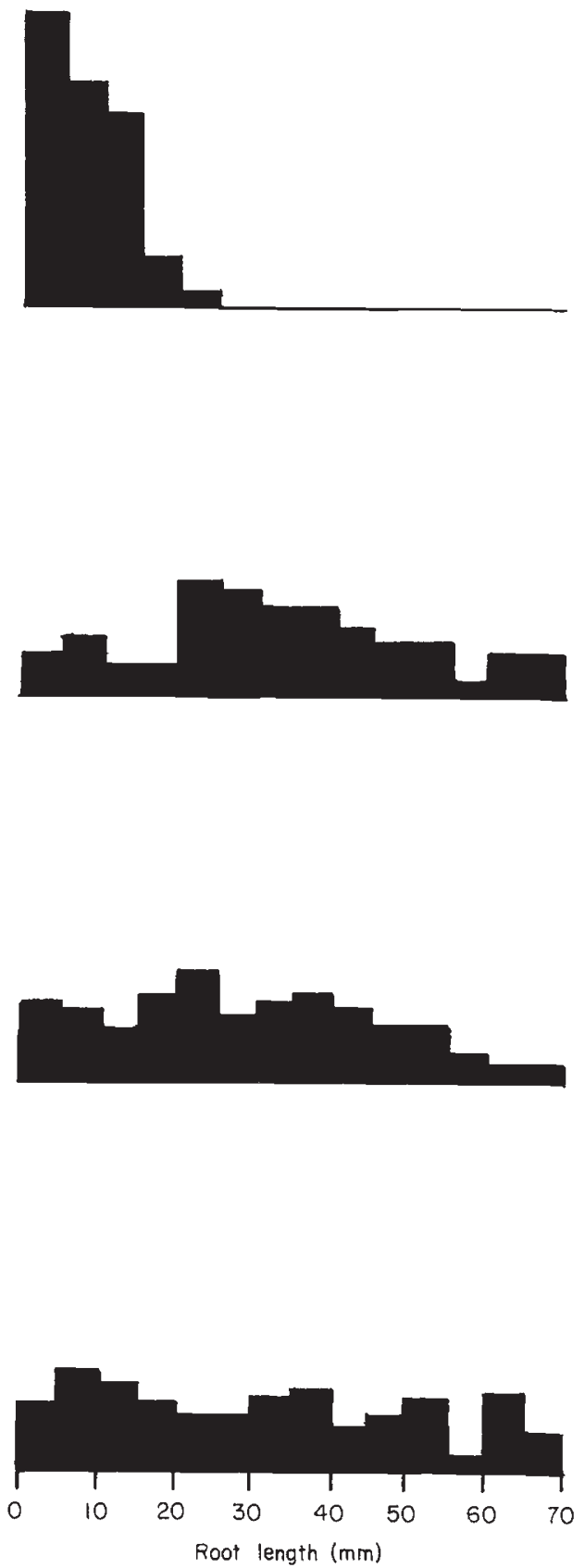

Fig. 6 Experiment 3 (iii). Root lengths of 100 randomly chosen seedlings of $\mathbf{S}_{1}$ (left) and $\mathbf{S}_{2}$ (right) generations of four Agrostis capillaris populations, screened at $20 \mu \mathrm{g} \mathrm{Zn} \mathrm{cm}^{-3}$.

generations of the populations from pylons ZK-50, ZK-51 and ZK-52.

A parallel increase was not found however in the case of the population beneath pylon ZK-180, in which selection was unable to bring about any improvement in zinc tolerance. This can only be due to the lack of genetic variability for zinc tolerance in the original unselected material of this population. This is reflected in the narrow sense heritability estimates of 0.10 , and 0.17 , for the $S_{1}$ and $S_{2}$ generations. These estimates do 
not differ significantly from zero, as would be expected for a population in which there is no significant response to two cycles of artificial selection for increased zinc tolerance.

It might be expected that adjacent pylon populations would have a genetic connection with each other as the result of gene flow so that tolerance could pass from tolerant individuals already established beneath some pylons to others where it had not. Adjacent pylons are about $300 \mathrm{~m}$ apart and the available evidence about patterns of gene flow suggest that effective pollen/gene flow over distances greater than $5 \mathrm{~m}$ is extremely limited (Jain \& Bradshaw, 1968). This effect is reinforced by the density of flowering of the recipient population, (Gleaves 1973), which in the case of subpylon populations of $A$. capillaris examined here is generally high. The populations are therefore effectively islands, and separate replicates of the evolutionary process.

It might be argued that since $\mathrm{ZK}-50,51$ and 52 are adjacent pylons on the same transmission line, this may have some bearing upon their similarities in having zinc tolerant populations beneath them, and their ability to respond to selection for increased zinc tolerance. It is possible that despite the distances between the pylons some degree of genetic integrity exists or has existed in the past between them because of gene exchange, or because they may have developed from the same initial colonizing population. This does not, however, alter the importance of the evidence of the contrast between $\mathrm{ZK}-50,51$ and 52, and ZK-180 for two reasons. First, many other pylons at least as distant from them as ZK180 also support tolerant populations, and secondly, a number of pylons with large bare areas beneath them for potential colonization remain bare, despite being surrounded by extensive stands of $A$. capillaris.

The significant fact is that the pylon populations are behaving very differently from each other from an evolutionary point of view. The evolutionary changes leading to the development of zinc-tolerant populations of $A$. capillaris beneath electricity pylons seems to have occurred beneath some pylons, but not beneath others. Since the same or very similar selection pressures must be acting at all sites with regard to tolerance, the data reported here provide (i) clear evidence for genetic constraints limiting evolution as suggested by Bradshaw (1984a, 1984b) and (ii) the stochastic nature of the evolutionary process because of randomness in the occurrence of the necessary variability. This is supported by the survey of occurrence of metal tolerance in different normal populations of $A$. capillaris carried out by Symeonidis et al. (1985).

The origin of the variation in the occurrence of tolerant individuals in the areas where pylons have been erected could not be examined, because the populations must all have developed within the last 500-600 years following forest clearance. The most likely explanation for its occurrence is a founder effect (Briggs \& Walters, 1982; Falconer, 1983), which operated in the colonizing process. This does not, however, alter the fundamental argument that the lack of tolerance beneath certain pylons is due to the lack of appropriate variability. Such a constraint is well known to plant breeders, but has received little attention from those working with natural populations. Stochastic variation in the occurrence of genes may be an important explanation of some of the more surprising cases of evolution, and the equally surprising cases where evolution might be expected but has not occurred.

\section{Acknowledgement}

S. A. Al-Hiyaly was supported by the Iraq Scholarship Directorate, which is gratefully acknowledged.

\section{References}

AL-HIYALY, S. E. K. 1989. Evolution of zinc tolerance under electricity pylons. Ph.D. Thesis, University of Liverpool.

AL-HIYALY, S. E. K., McNeILly, T. AND BRADSHAW, A. D. 1988. The effect of zinc contamination from electricity pylons evolution in a replicated situation. New Phytol., 110, 571-580.

AL-HIYALY, S. E. K., McNeILlY, T. AND BRADSHAW, A. D. 1990. The effect of zinc contamination from electricity pylons contrasting patterns of evolution in five grass species. New Phytol., 114, 183-190.

AnTonovics, J. 1986. The genetics and evolution of differences between closely adjacent plant populations with special reference to heavy metal tolerance. Ph.D. Thesis, University of Wales.

ANTONOVICS, J., BRADSHAW, A. D. AND TURNER, R. G. 1971. Heavy metal tolerance in plants. Adv. Ecol. Res., 7, 1-85.

BRADSHAW, A. D. 1975. The evolution of heavy metal tolerance in plants and its significance for vegetation establishment on metal contaminated sites. In: Hutchinson, T. C. (ed.) International Conference; Heavy Metals in the Environment, Vol. II, CEP Consultants Ltd, Edinburgh. Toronto, Canada, 299-322.

BRADSHAW, A. D. 1984a. Adaptations of plants to soils containing toxic heavy metals - a test for conceit. In: Evered, D. and Collins, G. M. (eds), Origins and Developments of Adaptation, CIBA, London, pp. 4-19.

BRADSHAW, A. D. 1984 b. The importance of evolutionary ideas in ecology and vice versa. In: Shorrocks, B. (ed.), Evolutionary Ecology, Blackwell Scientific Publications, London, pp. 1-25.

Bradshaw, A. D. AND McNeIlly, T. 1981. Evolution and Pollution, Edward Arnold, London. 
BRIGgS, D. AND WALTERS, S. M. 1982. Plant Variation and Evolution. Cambridge University Press, Cambridge.

ERNST, w. 1976. Physiological and biochemical aspects of heavy metal tolerance. In: Mansfield, T. A. (ed.), Effects of Air Pollutants on Plants. Cambridge University Press, Cambridge, pp. 115-133.

FALCONER, D. S. 1983. Introduction to Quantitative Genetics, 2nd edn, Longman, London.

Farrow, s. J. 1983. Population dynamics and selection in Agrostis canina on a small copper mine. Ph.D. Thesis, University of Liverpool.

GARTSIDE, D. W. 1973. The genetics of heavy metal tolerance in plants. Ph.D. Thesis, University of Liverpool.

GARTSIDE, D. W. AND McNEILLY, T. 1974. The potential for evolution of heavy metal tolerance in plants II. Copper tolerance in normal populations of different species. Heredity, 32, 335-348.

GLEAVES, T. J. 1973. Gene flow mediated by wind borne pollen. Heredity, 31, 355-366.

HEWITT, E. J. 1966. Sand and water culture methods used in the study of plant nutrition. C.A.B. Technical communication No. 22.

INGRAM, C. 1987. The evolutionary basis of ecological amplitude of plant species. Ph.D. Thesis, University of Liverpool.

JAIN, S. K. AND BRADSHAW, A. D. 1968. Evolutionary divergence among adjacent plant populations I. The evidence and its theoretical analysis. Heredity, 21, 407-441.

KARATAGLIS, s. 1980. Variability between and within populations of Agrostis tenuis with respect to metal tolerance.
Phyton, 20, 23-32.

KHAN, M. S. I. 1969. The process of evolution of heavy metal tolerance in Agrostis capillaris, and other grasses. M.Sc. Thesis, University of Wales.

McNEILLY, T. 1987. Evolutionary lessons from degraded ecosystems. In: Jordon, W. R., Gilpin, M. E. and Aber, J. D. (eds), Restoration Ecology, Cambridge University Press, Cambridge, pp. 271-286.

QUALSET, C. o. 1975. Sampling germplasm in a centre of diversity: an example of disease resistance in Ethiopian barley. In: Frankel, O. H. and Hawkes, J. G. (eds) Crop Genetic Resources for Today and Tommorow, Cambridge University Press, Cambridge, pp. 81-96.

SYMEONIDIS, L., McNEILLY, T. AND BRADSHAW, A. D. 1985. Interpopulation variation in tolerance to cadmium, copper, lead, nickel, and zinc in nine populations of Agrostis capillaris L. New Phytol., 101, 317-324.

THOMPSON, J. 1987. Population Biology of Anthoxanthum odoratum. Plantago lanceolata, and Rumex acetosa on zinc and lead mine spoil. Ph.D. Thesis, University of Liverpool.

WALLEY, K. A., KHAN, M. S. I. AND BRADShaW, A. D. 1974. The potential for evolution of heavy metal tolerance in plants I. Copper and zinc tolerance in Agrostis tenuis. Heredity, 32, 309-319.

WU, L., BRADSHAW, A. D. AND THURMAN, D. A. 1975. The potential for evolution of heavy metal tolerance in plants III. The rapid evolution of copper tolerance in Agrostis stolonifera. Heredity, 34, 165-187. 